RESEARCH ARTICLE

\title{
Student Affairs and Services during Covid-19 in Africa: Mitigating the Pandemic's Impact on Student Success
}

\author{
Birgit Schreiber, ${ }^{\mathrm{i}}$ Thierry M. Luescher, ${ }^{\mathrm{ii}}$ Brett Perozziii ${ }^{\mathrm{iii}}$ \& Lisa Bardill Moscaritolo ${ }^{\mathrm{iv}}$
}

\section{Abstract}

The Covid-19 pandemic has highlighted the challenges that present obstacles to equitable learning and development in higher education in various parts of the world. African higher education and Student Affairs and Services (SAS) are faced with a set of challenges that are in part related to the resources within the institutions and in part due the sociocultural context into which the institutions are embedded. It is with this background that this study explores the impact of Covid-19 on SAS in Africa, as part of a wider lens on SAS across the globe.

The study was conducted with an online survey which generated 781 responses of Student Affairs practitioners from across the globe, of which 118 were from the African continent. The data show SAS's critical role in mediating the various domains within and beyond the higher education institution that impact on student success. The domains that impact on student success include the students' personal experiences, the public domain, the sociocultural community and familial milieu, and the institutional/ SAS domain. Thus, this article discusses SAS's critical role in mediating the impact of these four domains on the student living and learning experience. The purpose of this article is to discuss the data and to use the data to gain insights into the way SAS has played a role in mitigating the impacts of Covid-19 in four domains relevant for student success.

Based on our findings, a systemic-contextual model is proposed that illustrates the relevance of four domains that need to synergise for students to be successful. Our data suggests that while SAS and universities do a great deal to support students in their learning, factors in the public domain, factors in the sociocultural community and familial milieu need to be conducive to learning to enable more student success in Africa.

\section{Keywords}

comparative international higher education; Covid-19; ICT in Student Affairs; personal factors; public infrastructure factors; sociocultural factors; Student Affairs theory

i Dr Birgit Schreiber is a member of the Africa Centre for Transregional Research at Alberts-LudwigUniversität Freiburg, Germany. ORCid: 0000-0003-2469-0504. Email: birgitdewes@gmail.com

ii Prof. Thierry M. Luescher is the Research Director for Post-schooling and Work in the Inclusive Economic Development Division of the Human Sciences Research Council (HSRC), Cape Town, South Africa, and Associate Professor: Higher Education affiliated to the University of the Free State, Mangaung, South Africa. ORCid: 0000-0002-6675-0512. Email: tluescher@hsrc.ac.za

iii Dr Brett Perozzi is Vice President of Student Affairs at Weber State University, USA. ORCid: 0000-0003-1378-8223. Email: brettperozzi@weber.edu

iv Dr Lisa Bardill Moscaritolo is the Vice Provost for Student Life at the American University of Sharjah, United Arab Emirates. ORCid: 0000-0003-2809-0012. Email: 1moscaritolo@aus.edu 


\section{Introduction}

During the Covid-19 pandemic, Student Affairs and Services (SAS) has proved to be amongst the most responsive and relevant divisions in higher education institutions across the globe, seeking to mitigate the impact, and engage with and provide students with development and support (McCarthy, 2020). In every world region and in different countries and institutions, SAS's ability to respond to Covid-19-related health scares and government-imposed precautions and restrictions has been impacted differently depending on a range of factors, including higher education structures and regulatory bodies, culture and resources, sociopolitical factors, size and shape of institution, and the demographics of the student body and student characteristics (Aristovnik et al., 2020). Some students were left with laptops, mobile devices and phones, data packs and Wi-Fi codes and some with even less (Schreiber et al., 2020).

Many African ${ }^{1}$ universities closed and left students to wait for further instructions (Crawford et al., 2020; Tesar, 2020; UNDP, 2020). Even though some universities in Africa rallied to provide online teaching, what is beyond the remote teaching and learning model are infrastructure and network holes, social-cultural inequities, and social-community environments that have "toxic social norms" (UNDP, 2020, p. 8) which may render a home environment unconducive to learning. It is this combination of challenges that has made remote learning away from the university campus extremely hard for some students, especially those from the most disadvantaged sections of society for whom attending a university offers a unique avenue for upward social-economic mobility (Heckman \& Mosso, 2014; Marope, 2019). When students step off campus into significant social inequalities or only access education via online modalities, the tool of empowerment and emancipation, especially for vulnerable groups, is impaired (Altbach et al., 2010, p. 31). Accessing higher education was already a challenge for many vulnerable groups (Marinoni, 2020; Schendel \& McCowan, 2016; UNDP, 2020), but with Covid-19 it has now become an even greater hurdle (Humphrey, 2020; Marinoni, 2020; UNDP, 2020, p. 9) whereby the pandemic is likely to widen the gender gap, increase teenage pregnancies, reduce participation in self-determination for many and cause significant setbacks for human development in Africa (UNDP, 2020).

SAS is instrumental in paving the way for student access, student persistence, retention, and success through its impact within and on institutions and through the support it provides to students in general, and particularly to certain student populations that require special services and required contextual conditions conducive for learning (Ludeman \& Schreiber, 2020; Osfield et al., 2016). The overarching function of SAS in higher education across the globe is to contribute to equitable opportunity and support a developmental

1 'Africa' is used here as a collective continental term and for purposes of this study is used as part of the regional nomenclature suggested and used by UNESCO, including Asia, Europe, Middle East, Oceania, North America and South America (UNESCO, 2018). The authors note that the terminology and naming of these world regions are somewhat problematic and simplistic, are imprecise, are culturally, geographically and politically biased, susceptible to misrepresentation and tend to be Anglo-centric (see, for instance, Somerville's discussion on the "many histories of the continent" $(2017$, p. 6). 
model of higher education in pursuit of the global as well as national social justice and human development agenda (Ludeman \& Schreiber, 2020). By promoting student engagement, enabling compatible living and learning contexts, providing health care and counselling, offering housing and residence life programmes, facilitating social, learning and personal safe spaces, implementing co-curricular programmes for students to learn beyond their discipline and develop into healthy, critically thinking, active citizens, by mapping learning and career pathways and supporting students to overcome their unique challenges, SAS ensures equity and fairness on the campuses of institutions in our massified higher education systems (Kuh et al., 2005; Ludeman \& Schreiber, 2020; Luescher-Mamashela, 2011; Pascarella \& Terenzini, 2005). Covid-19 has issued a massive challenge to SAS in Africa to be able to still provide its various engagement, social justice, and developmental functions in the face of emergency remote teaching.

In this article, we explore a range of different impacts that Covid-19 has had on the role and function of SAS in Africa, especially focusing on SAS service provision, involvement in institutional and national decision-making, resources, vision, and mission. For this purpose, we explore and discuss the results of the Global Covid-19 Student Affairs and Services Survey, paying special attention to responses received from African student affairs practitioners.

Based on our findings, we propose a systemic-contextual model that illustrates the importance of four domains that need to be functional for students to be successful. While SAS contributes significantly to making universities inclusive and supportive spaces conducive to student development, our data show that factors in the public macro context, factors in the social-cultural milieu, and factors in the community context need to be favourable to learning to enable sustained student success in Africa.

\section{Theory and Practice of Student Affairs and Services}

The theory and practice of Student Affairs have developed unevenly across the globe because of different levels of higher education development, differences in the historical origin and context-specific emphases of national higher education systems, institution-level variations, and different ways in which SAS relates to higher education and how epistemic communities and discourse has evolved, making this a 'low-consensus field' (Torres et al., 2019). However, the theory and practice of SAS tend to follow a trajectory observed widely by Pascarella and Terenzini (2005) from essentially an in loco parentis function of SAS to service delivery and extra-curricular programme delivery, and more recently towards embedded co-curricular programmes for students and the intentional pursuit of integrated systemic-institutional impact on higher education to shape the living and learning contexts of students. The Smith's 2019 summary of '60 years of scholarship' highlights the breadth and depth of research and knowledge of SAS (Smith, 2019).

Learning and development does not occur in isolation but within a context where many factors play together to create adequate conditions for learning and development to take place (Tinto, 2014). Students are sandwiched at the intersection of these factors, and while impacted by these, students simultaneously and dynamically respond to and impact 
them in turn. It is this systemic-dynamic and contextual understanding of the ecology of learning that provides a framework for understanding this research into the impact of Covid-19 on SAS in Africa.

Theories and practices in SAS have mainly emerged from the USA and have been developed further in these and other contexts and can be broadly clustered into developmental theories and environmental impact theories of student learning and development (Pascarella \& Terenzini, 2005; Tinto, 2014).

The developmental theories of SAS concentrate on the individual-socialpsychological changes of students before, during, and after higher education, focusing on the cognitive, moral, psycho-social and identity development of late adolescence and early adulthood (Pascarella \& Terenzini, 2005). These developmental theories are made up, for instance, of Perry's stage theories, Baxter-Magolda's identity development theory, and Gilligan's moral development as well as Chickering's vector model of college student development (Pascarella \& Terenzini, 2005). According to these theories, the SAS focus on student development in all its facets emphasises the students' development towards achieving autonomy and independence, theorising the intra- and inter-personal factors that are affected by living and learning influences and their interplay (Hamrick et al., 2002).

The environmental impact theories of student success broaden the scope of impact on student development from intra-psychic and inter-social to include the contextual, thus making student development a shared responsibility between environmental impacts and students. Agency for success is in each student where the site of development occurs, but also, and critically so, foregrounds the environmental and contextual factors into which the student is embedded. The environmental impact theorists of student success, comprising Tinto, Astin, Pascarella, Weidman, Kuh and others, all focus on the interplay of at least three influences that impact on a meaningful educational experience, albeit with different emphasis: (1) personal-cognitive resources of the students; (2) institutional-teachinglearning inputs; and (3) familial-social influences and social norms, into which the students' learning and development experiences are embedded. These three sets of influences need to converge to support the success of higher education and the success of students.

Astin $(1993,1996)$ proposed the Input-Environment-Outcome (I-E-O) model, based on Kurt Lewin's famous equation of $\mathrm{B}=\mathrm{F}(\mathrm{PxE})$ - stating that behaviour is the result of the interaction of the person with her/his environment. Astin's (1977) notion of 'student involvement' along with Tinto's 'student retention' $(1997,1998)$ highlight the critical importance of students' connectedness, integration, and inclusion into communities of learning, all of which are key determinants of persistence and retention (Mannan, 2007; Hamrick et al., 2002). In Astin's model, the 'E' includes all staff, students, practices and policies, institutional cultures, and social contexts that impact on the student. Astin famously declared that "students learn by being involved" (Astin, 1985, p. 133) in the living and learning experience.

Tinto's integrative model has been described as "the most influential model" of environmental impact theories (McCubbin, 2003, p. 1). It highlights the students' interaction with the university context and coined the now ubiquitously used concept of 
'learning communities', thus firmly shifting the focus towards the complimentary relationship between social integration and academic integration of students as fundamental to student success, including the critical role that student living contexts play (Mannan, 2007; Tinto, 2014; Schreiber, Luescher \& Moja, 2019). Tinto (1993, p.12) described his "integrative model" as primarily "sociological" in that students' intentions are continuously shaped by academic and social structures. In a study by McCubbin (2003), the correlation between integration and student success was less convincing for mature and returning students, but the relevance of integration for first time entering student has been firmly established (Pascarella \& Terenzini, 2005; Kuh et al., 2005, 2009, 2010; Strydom et al., 2017).

Weidman $(1984,1989)$ expanded on Astin's and Tinto's models and included formal and informal influences of family and community as critical contributors to student success and termed these "undergraduate socialisation factors" (Weidman, 1989, p. 299). Weidman (1989) emphasised the synergy of micro and macro factors including factors beyond the ambit of the higher education institution, including society's role in student success.

Kuh $(2005,2009,2010)$ seminally theorised and researched student engagement that has become the global measure of integration of students in their learning environment (Trowler, 2010; Coates, 2007). Student engagement, although critiqued for focusing on higher education institution-centric engagement practices (Trowler \& Schreiber, 2020), has become a strong correlate of student success (Trowler, 2010; Coates, 2007). It is the interactions with academic staff (i.e. professors, lecturers, and teaching support), peers, and with the out-of-class experience that are reliable correlates of student success (Kuh et al., 2005, 2010). Some of the expansions of student engagement include the notions of oppositional engagement (Altbach et al., 2010; Trowler \& Schreiber, 2020; Case, 2007; Luescher, 2017, 2018) that include discussions of oppositional behaviours, which nonetheless are behaviours and intentions that connect with the wider living and learning context.

Researchers from South Africa have shown that the experiences of alienation play a critical negative role in student persistence (Carolissen \& Kiguwa, 2018; Case 2007). Scott $(2009$, p. 27), remarking on the South African higher education context, highlights that a "co-ordinated approach" is required and Lange (in Swingler, 2018, n.p.) states that "the interface between students' psychosocial and academic worlds is mediated by several services and infrastructures that are not in sync, and some of which operate as if the others did not exist".

Carollissen and Kiguwa (2018) highlight the importance of 'belonging' as a critical factor in theorising about student experience and student persistence and the role of alienation is also cited as a critical factor by others (Bozalek \& Boughey, 2012; Davids, 2020). More broadly, the United Nations Human Development Reports point towards factors in the context of the student's life, including social norms, home life, safety and security, access to amenities and technology (UNDP, 2020) as critical in shaping a conducive environment for male and particularly female students' success. 


\section{Methodology}

The purpose of this study has been to gather and explore responses of SAS practitioners and professionals on how Covid-19 impacted their ability to respond to factors that affect student learning and development during the pandemic, and the extent to which they engaged in university decision-making and supported students. Through the lens of systemic-environmental impact theories, we seek to understand the factors that impact on SAS to support student development. For this purpose, our research employed a survey and online questionnaire, designed in Qualtrics, with a combination of closed response questions and open text answers. The quantitative data was analysed in SPSS (Statistical Package for the Social Sciences) producing descriptive statistics, and the qualitative responses were explored using content and thematic analysis in NVivo.

\section{Sampling and sample}

Survey respondents were sourced by virtual snowball sampling, also called chain sampling, chain-referral, or referral sampling (Creswell, 2013), which is a nonprobability sampling technique. The sample generated is a non-random, non-representative but stratified convenience sample, and does not represent a statistically representative group. This kind of sampling enabled us to seek information during extraordinary conditions, and to seek information from potentially hard-to-reach groups (see how to survey hard-to-reach populations at https://inclusivegrowth.be/downloads/output/ms87-m20-5-hard-tosurvey-groups.pdf and surveying non-random and non-representative samples at http:// www.sociology.org.uk/notes/SocShortcuts_methods16.pdf). This kind of sampling enables theory development and hypothesis development rather than hypothesis testing. We aimed to generate hypothesis and to generate theory, describe and compare data to gain insights, based on the data, rather than making statistically reliable generalisations.

In our case, potential respondents were sourced via virtual social and professional networks, via emailing and via acquaintance pathways. Email was the primary mode of communication when initially contacting processional associations, who were encouraged to engage their members and share the request to participate with them. Other distribution avenues were SAS personal and professional national and global networks and acquaintance pathways where colleagues were asked to complete the survey and forward the request to others. Social media was used (Facebook, LinkedIn, Twitter) to further the potential reach of the survey. This method facilitated rapid responses that reached a level deemed adequate for statistical purposes and for meaningful interpretation (Goodman, 2011; Salganik \& Heckathorn, 2004). This allowed us to reach regions that may not have responded well to postal services and assisted where the list and identity of participants was unclear (Baltar \& Brunet, 2012; Salganik \& Heckathorn, 2004).

One potential limitation of this method is that although it increases participation, bias might be towards participants who comfortably use online media, neglecting responses from subjects who are either not using online media readily or do not have access to online media as might be the case in some areas where Wi-Fi is fragile or only intermittently available, or are otherwise prevented from participating in online data gathering. 


\section{Sample}

The realised sample were 781 SAS practitioners who responded, either in full or in parts, to the online questionnaire, completed the consent form, and closed their responses, thus consenting and including themselves in the survey. The respondents hail from the following regions, as identified from their IP address (Table 1). The researchers used UNESCO (2018) and the International Association of Student Affairs and Services (IASAS) geographical regions as the primary guide to world regions. For the purpose of global comparison, these UNESCO regions have been used widely and yet pose complex challenges around misrepresentations of cultural or political homogeneity in these regions (see footnote in the introduction of this article). The 118 responses from across the vast African continent discourage reliance on statistical confidences, but nonetheless enable theorising about the data.

Table 1: Respondents by World Region

\begin{tabular}{|l|c|}
\hline Region & Number of respondents \\
\hline Africa & 118 \\
\hline Asia & 144 \\
\hline Europe & 207 \\
\hline Middle East & 35 \\
\hline Oceania & 108 \\
\hline North America & 149 \\
\hline Latin America and Caribbean & 20 \\
\hline Total & 781 \\
\hline
\end{tabular}

Table 1 shows that inter-regional comparison is possible because in all regions there are more than 100 responses, except Latin America and the Caribbean (LAC) and the Middle East.

The respondents were asked about their professional seniority/position in SAS. Figure 1 illustrates the relative positions and/or seniority of respondents. Titles and organisational conceptualisations/structures vary widely globally, and variation is evident in the data. Although not everyone completed this question, most respondents (47\%) identified as mid-level to senior SAS managers. The next largest grouping of respondents (39\%) were officers or in entry-level positions. The smallest percentage $(14 \%)$ were the most senior SAS position in their institution. 


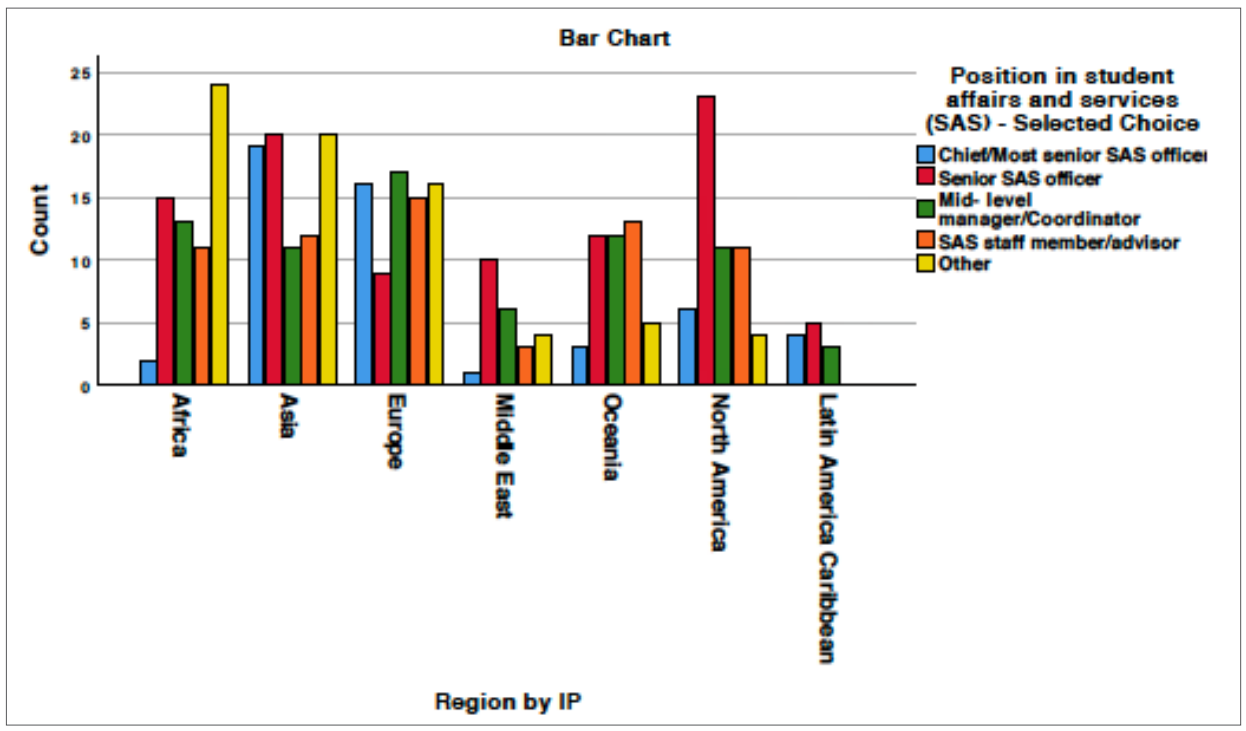

Figure 1: Respondents by seniority/position

In addition to asking about seniority/position, we asked the respondents about the number of years they have been working in SAS. Table 2 below shows how the African sample compares to the rest of the regions in terms of years of experience working in SAS. Overall, the African respondents, as well as respondents from Asia, have been working slightly fewer years than those in other world regions.

Table 2: Respondents by number of years working in Student Affairs

\begin{tabular}{|l|r|r|r|r|r|r|r|r|}
\hline & Africa & Asia & Europe & $\begin{array}{c}\text { Middle } \\
\text { East }\end{array}$ & Oceania & $\begin{array}{c}\text { North } \\
\text { America }\end{array}$ & LAC & Total \\
\hline $1-5$ & $46 \%$ & $50 \%$ & $30 \%$ & $9 \%$ & $34 \%$ & $15 \%$ & $25 \%$ & $34 \%$ \\
\hline $6-10$ & $21 \%$ & $24 \%$ & $21 \%$ & $26 \%$ & $23 \%$ & $11 \%$ & $25 \%$ & $21 \%$ \\
\hline $11-15$ & $13 \%$ & $12 \%$ & $19 \%$ & $35 \%$ & $11 \%$ & $26 \%$ & $17 \%$ & $17 \%$ \\
\hline$>15$ & $20 \%$ & $14 \%$ & $30 \%$ & $30 \%$ & $32 \%$ & $48 \%$ & $33 \%$ & $28 \%$ \\
\hline Total & $100 \%$ & $100 \%$ & $100 \%$ & $100 \%$ & $100 \%$ & $100 \%$ & $100 \%$ & $100.0 \%$ \\
\hline
\end{tabular}

\section{Data collection and analysis}

As noted above, data was collected via an online questionnaire, which contained a total of 53 questions. They were made up of (1) nine questions dealing with SAS decision-making in higher education institutions in the context of Covid-19; (2) four questions on SAS engagement with pandemic related issues; (3) three questions on the pandemic's financial implications; (4) three questions on predictions of how the pandemic will affect SAS. The questionnaire included eight questions on residence halls/student accommodation, eight questions on working online and instittuaional preparation, three questions on engagement 
and communication with students, and seven questions on the impact on particular student groups. Demographic questions were included at the end. Not all questions needed answering and a variety of question types were included such as closed choice options (most using Likert scale), open-ended questions, ranking and graded questions (e.g., full, partial, no/none). The survey was open for one month (May, 2020).

The data results were statistically analysed using SPSS, which offered the use of statistical functions, including frequency tables, cross-tabulation and a granulated examination of data, with special emphasis on data from African responses. Text responses were exported into the qualitative data analysis program NVivo. We then coded the open-ended responses using this software for thematic analysis.

\section{Ethics}

The research methodology and all written materials (i.e. informed consent form, questionnaire, project outline) were submitted to the institutional review board of the American University of Sharjah, United Arab Emirates (which is the home institution of one research team member) which granted full research ethics approval on 29 April 2020.

\section{Limitations}

Creswell discusses the inherent limitations in online surveys (Creswell, 2013). Online surveys, by definition, only include those who have access to the survey which may bias the sample. However, given that the situation around Covid-19 presented challenges around paper responses, we opted for this avenue for data collection and are noting the non-representation of this sample. In terms of using countries and continents as respondents' identifier it may have been preferable to use countries to capture richer and more textured data. However, low sample size per country compromised this option.

\section{Results of the Global SAS-Covid-19 Research: Spotlight on Africa}

The coronavirus pandemic has compelled universities around the continent and the world to send their students home and, in most cases, switch to some form of emergency remote teaching. Over a remarkably short period of time, academics and SAS professionals devised creative ways to deliver learning and support to students (Schreiber et al., 2020). However, what could not be fixed in many cases in the emergency remote teaching and learning model were stubborn social-public infrastructure and mobile network insufficiencies, substantial social-cultural inequities and social-community environments that are not conducive to learning and, in some cases, present barriers to learning. With African responses to this global Covid-19 survey as the focus, we concentrate in on these questions that deal with the systemic context of student learning and development during Covid-19. The data from 'Africa' is not viewed as statistically sufficient nor significantly representative to allow confident generalisations, but rather, offer an avenue to understand and illuminate the issues around responses to Covid-19. The insights gleaned from the data are discussed below. In addition, a more textured comparison of Africa with the other five regions of 
the world is beyond the scope of this article, but will be the focus of other publications emanating from this global research.

\section{The impact of Covid-19 on different student groups}

Covid-19 impacted on a number of student groups more severely than others. Figure 2 shows a word cloud of the open responses from SAS practitioners across Africa of which students were the most affected. At the centre and with the most frequent response were 'poor students' (14), followed by 'rural students' (8) and 'students with special needs' (7), such as students with disabilities and mental health challenges (5). Also specially impacted were students with no internet access at home (5), no devices (like tablet or laptops) (5) and those who remained on campus to study because their home situations were not conducive to learning (3). Other special student groups mentioned by African SAS practitioners were international students (4) and other students who studied far from home (5).

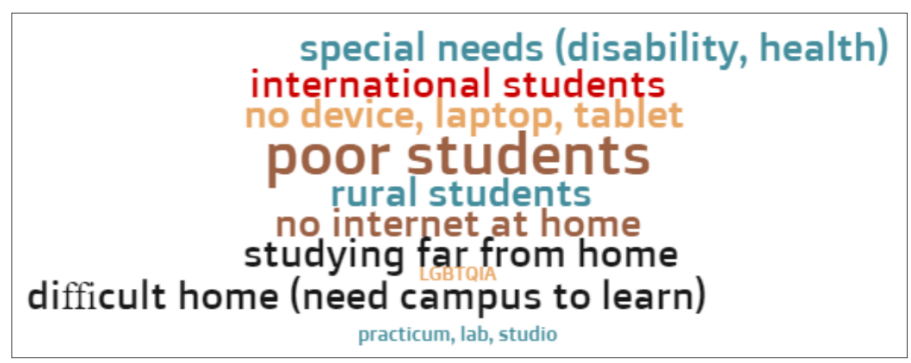

Figure 2: Most affected student groups in Africa $(\mathrm{N}=56)$

The African responses show interesting variations from the complete global sample. In both samples, 'poor students', 'students with special needs', and 'rural students' feature prominently. However, much more prominent in the global sample than in the African one is the group of 'international students' and especially 'Chinese and other Asian students' who have been affected greatly. In addition, in the global sample 'students who work to pay for their studies' and have lost their employment due to lockdown featured significantly, whereas this category of students is entirely absent in the African responses.

\section{Mitigating the financial impact and enhancing online access}

Given the widespread observation that poorer students have been more affected by Covid-19, a great deal of focus went to mitigating the financial impact. Whereas many universities in other parts of the world refunded students for costs such as student housing, tuition, and other fees including parking, in Africa, universities provided much less frequent financial relief to students by means of refunds (see Figure 3). This might well be due to the funding models at African institutions where government bursaries fund university costs and thus a refund would not go directly to the student but would be reimbursed to governments (see, for instance, the South African National Student Financial Aid Scheme funding model, [NSFAS, 2020]). 


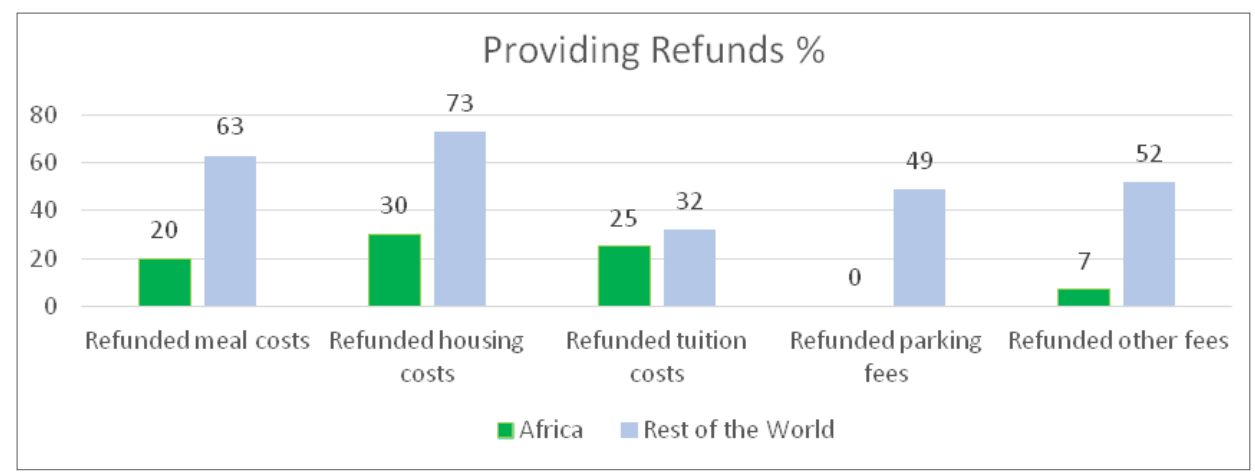

Figure 3: Providing financial relief by means of refunds $(\mathrm{N}=663)$

As Figure 3 shows, African universities rather mitigated the impact of Covid-19 financially by providing more directed financial relief to students (such as transport funds, funds for data and online devices, etc.; see Figure 4) than seen globally.

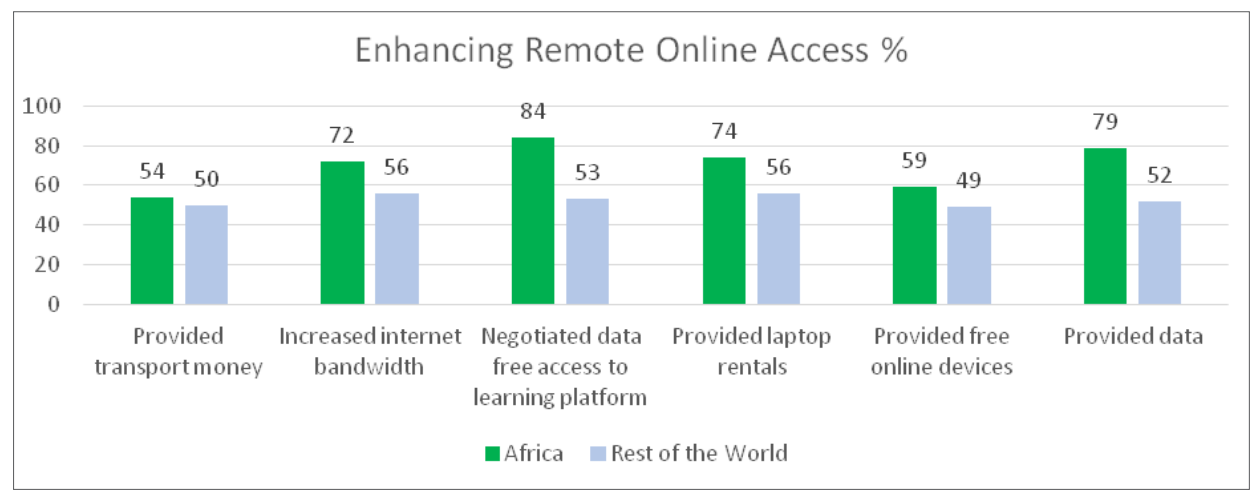

Figure 4: Enhancing students' remote online access $(\mathrm{N}=663)$

In the context of Covid-19-related lockdowns and other restrictions, African universities helped their students with transport money at about the level seen elsewhere in the world. However, African universities provided much more frequently than elsewhere in the world direct and targeted support to enhance remote online access to students who needed such support. This they did primarily by means of (1) increasing their institutional internet bandwidth; and (2) negotiating reduced data costs or a zero-rating for their websites and learning platforms; (3) procuring laptops and other learning devices for needy students; and (4) by directly providing data to students. In this respect, being mindful of the observation that poor students and students in remote and rural areas were the most affected (see Figure 2 above), African universities focused their (financial assistance) on these students to enhance their access to learning. This is in line with the social justice mandate of universities and SAS in particular (Schreiber, 2014), where access to learning for particularly vulnerable groups is foregrounded. 


\section{An essential partner in decision-making and service delivery}

Overall, when asked whether Student Affairs was considered "a key player in institutional decision-making" during the pandemic, $77 \%$ of African practitioners agreed or strongly agreed (which is comparable to similar levels elsewhere). Overall, slightly less frequently than the rest of the world, certain SAS services were declared essential $67 \%$ Africa vs. $76 \%$ rest of the world). Figure 5 shows the variation between different services and world regions.

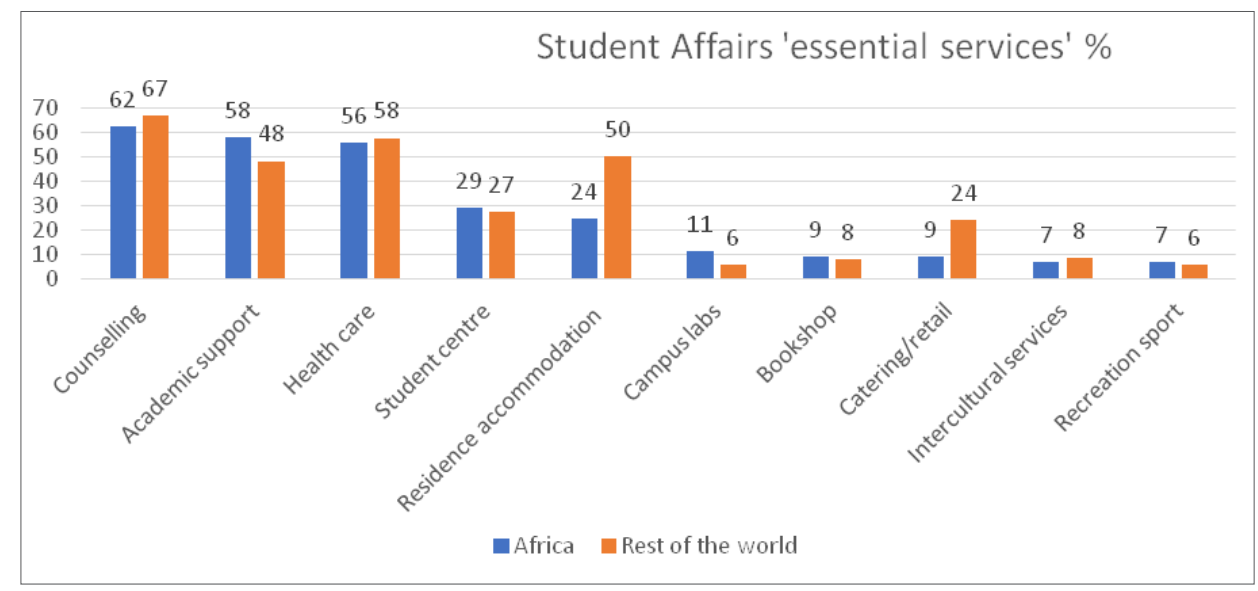

Figure 5: Student Affairs essential services $(\mathrm{N}=288)$

Figure 5 shows interesting variation. Firstly, it is evident that a similar range of SAS services were declared as 'essential services' during the national lockdowns across the world. Of those, globally and in Africa, the top three essential services were: counselling, academic support and health-related services. A thought-provoking variation in the data is that in Africa, student accommodation and related catering and retail services were considerably less frequently declared essential than elsewhere in the world. Conversely, academic support was mentioned slightly more frequently as an essential service in African universities than in the rest of the world.

\section{Innovative responses, mistakes and challenges}

The respondents also indicated many innovative ways in which they managed Covid-19 that can be grouped into six categories as indicated in Figure 6.

Figure 6 illustrates that SAS practitioners in Africa found the rapid move towards online provision of teaching and learning, student development, and support services a most innovative way of responding to the threat of Covid-19. Existing e-platforms were used as well as other ways to reach students. Respondents also mentioned a number of social media and communication platforms including Teams, WhatsApp, Zoom for interactive life communication as well as email and other social media for communication. 
Another frequently noted category of innovative responses relates to the institutional lockdown itself and related initiatives, such as the immediate deep cleaning and fumigation of campuses, organising travel for students, and implementing working from home policies for staff to continue work. African SAS staff also considered the responses to enhance equal online access (noted above in Figure 4) as innovative responses, such as providing devices and data to students who needed such, and communicating frequently and transparently using multiple platforms and addressing various constituencies, including staff, students, specific student populations, and student organisations.

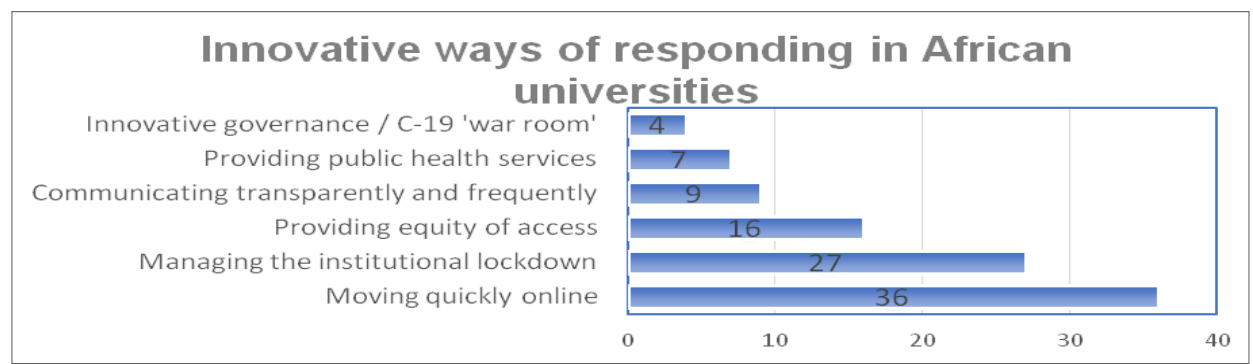

Figure 6: Innovative ways of responding to the pandemic in African universities $(\mathrm{N}=99)$

Moreover, African universities offered public health services of various kinds. SAS staff particularly noted: the dissemination of health-related information, using university facilities for quarantine, training health workers, keeping the campus clinics open, and offering medical students as health volunteers. Finally, there were management-related innovations such as reorganising workstreams to suit an online work environment, and establishing coordinated task teams including a central 'Covid-19 response room'.

Correspondingly, mistakes were identified by respondents. African SAS practitioners' coded responses particularly mentioned mistakes with respect to consultation and involvement in decision-making of students and staff. In the case of students, this caused resistance with respect to the implementation of some decisions and delays in the adoption of online learning in some cases. With respect to staff, an argument was that SAS mid-level staff should have been more involved. Institutional 'mistakes' were also noted with respect to the IT infrastructure of the institution; the eLearning platform's fragility and crashing due to overload; staff not being sufficiently trained; and communication not always being adequate.

It is especially these responses of 'mistakes made' that contributed to the development of the systemic-contextual model of SAS presented here. For example, one respondent noted that: "Only post grads, post docs and the academic research community can successfully work from home. Most people can't, due to numerous socio-economic and even sociopsychological issues."

This quote draws attention to the socio-economic challenges (of household level poverty) and socio-psychological issues (of personal, familial and communal factors) involved in determining whether the home is conducive to learning and working from 
home. Added to this comes a comment on 'mistakes made' from another respondent who points to the macro infrastructure challenges confronting students at home: "What we could call a mistake is actually a societal problem that is related to power supply and connectivity to the internet; these serve as bottlenecks to accessing the eLearning by some students." Both these responses from participants point directly to the role of influences beyond the institution that are critical in enabling or presenting barriers to student success.

\section{Discussion}

The higher education sector has been shaken by the Covid-19 pandemic and supporting the institutions and students across Africa has been an unprecedented challenge. SAS has been instrumental in a variety of ways in responding to and mitigating the impact of Covid-19 on the learning and development context, by supporting the change to virtual learning, providing digital access and support for online learning competencies, maintaining safe spaces on campuses conducive to learning and development, reaching out to rural students and supporting poor students, offering personal, academic, and social counselling and health care, and responding swiftly and innovatively to the various needs of students and the institution.

The data reveal a compelling relationship between SAS and the systemic-contextual factors and their impact on student success. The factors that impact on student learning and development include the personal domain of students, the sociocultural milieu into which they are embedded, the university at which they are enrolled, and the public macros structures which support basic services and functions. SAS is organisationally, conceptually and practically integrated into institutional processes, especially the teaching, living and learning spaces, and this makes the SAS mediation of academic-disciplinary process for student learning particularly relevant.

Figure 7 summarises the discussion and represents the factors explored in this study. The authors assert that individual student development is the result of the dynamic interplay of four 'systems' or 'domains' that are interrelated. These include (1) personal: internal intra-personal factors (such as motivation, intelligence, persistence, optimism, and 'grit' (Wilson-Strydom, 2017); (2) sociocultural: the family and social-cultural milieu including social norms, beliefs, and cultural practices; (3) academic-faculty: living and learning experience, institutional culture and practices, teaching and learning frameworks, epistemological access, SAS is closely related to this factor, and (4) public: macro systems, including basic service infrastructure such as electricity, water, shelter, health, safety, internet access, etc.

SAS is centrally involved, albeit to different degrees and in different ways, in mediating these four systems/domains to enable, facilitate and improve the learning experience of the student. The SAS mediates, mitigates, facilitates and improves these domains' impact on the students' (and institutional) success. The student, centrally located and sandwiched amongst these systems, navigates these domains and SAS is a key supportive role player in this navigations process. 
Each factor is mediated differently by SAS, overlaps and often is jointly impacted by SAS. For instance: the SAS and academic-faculty influence on student learning is, in some institutions, closely related and integrated, is well-coordinated and aligned to synergise to enable conditions conducive to student learning and development, together shaping a learning and development context. Yet in other institutions, SAS mediates and facilitates student support 'outside of academic processes' to promote access for disability, facilitate learning programmes, and offer orientation and academic support programmes. SAS is involved in mediating the social-cultural domains of students by assisting minority students who may be exposed to social-cultural challenges, including gender-based difficulties, and by providing accommodation. SAS supports students on a personal basis, by offering health and counselling services. During Covid-19, SAS was particularly active around support for public services, including access to Wi-Fi and mobile devices, facilitating transport and offering safe spaces for students who lived in precarious contexts.

The theoretical dimensions, including the developmental theories and environmentalimpact theories, as well as insights from the survey, all integrate to give a holistic understanding of the SAS impact on different domains of student learning and development.

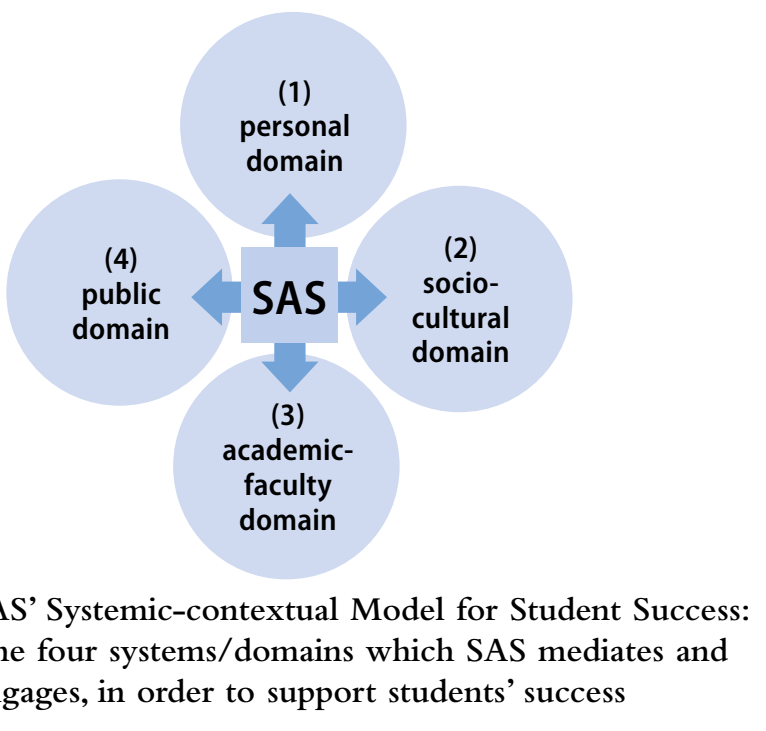

Four identified domains - the personal, social-cultural, public, and the academic-faculty domain - need to converge to support student persistence and success. SAS is centrally involved in mediating these four domains for students and mitigating any subverting influences the domains may have on students' ability to persist and succeed in a meaningful learning and development experience. The four domains are simultaneously contextual, meaning that they shape the situation and environment, and also systemic, meaning that they dynamically and reciprocally impact each other (i.e., are not discreet but mutually influential). What emerges from the data is that SAS is critically involved, with varying 
degrees and emphasis, depending on institution, context and sociocultural environment of the students, in mediating the living and learning context for students.

The personal domain includes the personal characteristics, abilities, motivations, preparedness and resources that students bring towards their success. Examples include engagement (Kuh et al., 2005, Strydom et al., 2017), academic preparedness (MonnapulaMapesela, 2017), motivation and grit (Wilson-Strydom, 2017) which have been widely researched and are evidently linked to student success.

The public domain includes the macro infrastructure, economic and political influences and factors, resources and provisions that are typically provided at public/ municipal/city level, including electricity, water, transport, health care, public order and safety, sanitation, and essential social services (UNDP, 2020). Included here are Wi-Fi networks, even if provided by private corporations, as these rely on a myriad of public service functions listed here. These public service provisions are powerful influences on the student's chance of success.

The sociocultural domain refers to the social and cultural practices and attitudes, at community and family level, which include religious prescriptions, gender roles and expectations, and norms ranging from the explicit to the unspoken. These social and cultural values powerfully impact student success, and can either support and accelerate or present barriers.

The academic-faculty domain is focused on the institutional learning and teaching strategies, the resources and institutional culture and practices, the size and shape of the learning environment and the academic engagement practices prevalent. The relational interplay of the various epistemological fields in higher education include the formal administrative, discursive-academic and informal experiential domains of students in their development and learning experience (Bernstein, 2000; Schreiber, 2013). Here, SAS is typically very powerfully influencing student success.

These four domains - the personal, the public, the sociocultural and the academicfaculty domain - are mediated by SAS in a variety of ways. The domains work synergistically, both negatively and positively, and the data reveals that SAS in Africa, with the onset of Covid-19, is critically relevant in organising responses that mitigate these impacts to shape a more supportive context for student success.

The data shows that SAS supported personal functioning of students (for instance by providing more and online counselling, etc.), mitigated the public service provision failure (for instance by providing free access and online mobile devices, etc.), compensated for sociocultural practices that were less conducive for studying (for instance by providing safe accommodation where communities and households had toxic influences on students, etc.), and facilitated learning (for instance, by offering tutorials and academic support, etc.).

By using data from the survey, the relevance of SAS's role and function vis-à-vis the personal, public, sociocultural, and academic-faculty impacts on students' learning and development is demonstrated. Overall, SAS mediates the students' experience which is nestled into these domains. SAS facilitates access, dilutes barriers, compensates for omissions 
and augments the living and learning experience for students, thus advancing student success. The overarching social justice agenda of SAS, i.e. to level the playing field, to enable fairer conditions and to support more equitable access to educational experiences, is grounded in the SAS's mediation of these four domains.

The context beyond the university has never been more important than during Covid-19 times, and this includes the macro public infrastructure, societal norms and practices, community-based structures and familial milieu, and all that makes an environment more - or less - conducive to a meaningful learning experience. There is a strong association between higher education attainment levels and higher levels of social equity and human development (Peercy \& Svenson, 2016; UNDP, 2020). Higher education is a tool for human development but 'it takes a village' - a community with functional structures and supportive social norms - to enable higher education to deliver on its promise.

\section{Conclusion}

The analysis of the data in this research enabled insight into the domains that are mitigated by Student Affairs and Services (SAS) in order to support student success. From the role and function of SAS, which emerged so cogently during Covid-19, we developed a systemic-contextual model of SAS for student success.

SAS's responses are unique, varied and tailored to compensate for the hindrances, explicit and invisible, systemic and situational, that students experience in their quest for a meaningful learning and development higher education experience. Particularly in Africa, the context is to varying degrees equipped to enable an environment conducive to student success. What emerges powerfully from this research is that it is precisely this context, including and beyond the higher education institutions, the sociocultural community, the familial milieu and the public domain into which the learning experience is embedded, that is particularly implicated in playing a significant role in student success. Universities are embedded into wider social and cultural communities and rely on family, community and public systems and it is these domains, together with the institutional and personal, that enable a context conducive to student success. African SAS theory development, based on empirical research, as is done in this article is urgently required to expand upon prevailing SAS theories and practices so that student success continues to be a significant national and continental development avenue.

SAS's influence on these factors that impact on student success is critical to sustained student success in Africa. Moreover, SAS needs to focus on equipping students to become social justice agents so that students themselves can powerfully impact on the personal, institutional, social, cultural and public influences on student success. Higher education offers a powerful learning and development experience for students and for this to be more meaningful, the four domains - the personal, the public, the sociocultural community and family milieu, and institutional - need to synergistically align to support student success. SAS plays a critical role in mitigating and harmonising these domains. 


\section{Potential Conflict of Interest}

The authors declare that they have no competing interest.

\section{Funding}

This research received no specific grant from any funding agency, commercial entity, or non-profit organisation.

\section{References}

Altbach, P., Reisberg, L. \& Rumbley, L. (2010). Tracking a global academic revolution. Change, 42(2), 30-39. https://doi.org/10.1080/00091381003590845

Aristovnik, A., Keržič, D., Ravšelj, D., Tomaževič, N. \& Umek, L. (2020). Impacts of the COVID-19 pandemic on life of higher education students: A global perspective. Sustainability, 12, 8438. https:// doi.org/10.3390/su12208438

Astin,A. (1977). Four critical years: Effects of college on beliefs, attitudes and knowledge. Jossey-Bass.

Astin, A. (1985). Achieving education excellence: A critical assessment of priorities and practices in higher education. Jossey-Bass.

Astin,A. (1993). What matters in college? Four critical years revisited. Jossey-Bass.

Astin, A. (1996). Involvement in learning revisited: Lessons we have learnt. Journal of College Student Development, 37(2), 123-134.

Baltar, F. \& Brunet, I. (2012). Social research 2.0:Virtual snowball sampling method using Facebook. Internet Research, 22(1), 55-74. https://doi.org/10.1108/10662241211199960

Bernstein B. (2000). Pedagogy, symbolic control and identity. Theory, research, critique, Vol. V. Rowman and Littlefield.

Bozalek, V. \& Boughey, C. (2012). (Mis)framing higher education in South Africa. Social Policy and Administration, 46(6), 688-703. https://doi.org/10.1111/j.1467-9515.2012.00863.x

Carolissen, R. \& Kiguwa, P. (2018). Narrative explorations of the micro-politics of students' citizenship, belonging and alienation at South African universities. South African Journal of Higher Education, 32(3). https://doi.org/10.20853/32-3-2542

Case, J. (2007). Alienation and engagement: Exploring students' experience of studying engineering. Teaching Higher Education, 12(1), 119-133. https://doi.org/10.1080/13562510601102354

Coates, H. (2007). A model of online and general campus-based student engagement. Assessment and Evaluation in Higher Education, 32(2), 121-141. https://doi.org/10.1080/02602930600801878

Crawford, J., Butler-Henderson, K., Rudolph, J., Malkawi, B., Glowatz, M., Burton, R., Magni, P. \& Lam, S. (2020). Covid-19: 20 Countries' higher education intra-period digital pedagogy responses. Journal of Applied Teaching \& Learning, 3(1), 120. https://doi.org/10.37074/jalt.2020.3.1.7

Creswell, J. (2013). Research design: Qualitative, quantitative, and mixed methods approaches. Sage.

Davids, N. (2020). The consequences of increasing student alienation in higher education institutions. https://www. researchgate.net/publication/339975135_The_consequences_of_increasing_student_alienation_in_ higher_education_institutions

Goodman, L.A. (2011). Comment: On respondent-driven sampling and snowball sampling in hard-toreach populations and snowball sampling not in hard-to-reach populations. Sociological Methodology, 41(1), 347-353. https://doi.org/10.1111/j.1467-9531.2011.01242.x

Hamrick, F., Evans, N. \& Schuh, J. (2002). Foundations of student affairs practice: How philosophy, theory and research strengthen educational outcomes. Jossey-Bass. 
Heckman,J. \& Mosso, S. (2014).The economics of human development and social mobility. Annual Review of Economics, 6, 689-733. https://doi.org/10.3386/w19925

Humphrey, D. (2020). Colleges must attend to three crucial areas. Inside Higher Ed. https://www.inside highered.com/views/2020/08/17/higher-ed-responds-covid-it-should-focus-three-areas-ensurequality-and-equity [Accessed 22 September 2020].

Kuh, G. (2009). What student affairs professionals need to know about student engagement. Journal of College Student Development, 50(6), 683-706. https://doi.org/10.1353/csd.0.0099

Kuh, G., Kinzie, J., Schuh, J. \& Whitt, E. (2010). Student success in college. Jossey-Bass.

Kuh, G., Kinzie, J., Schuh, J., Whitt, E. \& Associates. (2005). Student success in college: Creating conditions that matter. Jossey-Bass.

Ludeman, R. \& Schreiber, B. (2020). Student affairs and services in higher education: Global foundations, issues and best practices (3rd ed.). Deutsches Studentenwerk Publishers.

Luescher-Mamashela, T.M. (with S. Kiiru, R. Mattes, A. Mwollo-ntallima, N. Ng'ethe \& M. Romo) (2011). The university in africa and democratic citizenship: Hothouse or training ground? African Minds. https://doi.org/10.47622/9781920355678

Luescher-Mamashela, T.M., Moja,T. \& Schreiber, B. (2013). Towards a professionalisation of student affairs in Africa. Journal of Student Affairs in Africa, 1(1\&2), vii-xiii. https://doi.org/10.14426/jsaa.v1i1-2.18

Luescher, T.M. (2017). From student enragement to student engagement: What is your theory of change? HSRC Review, 15(2), 13-15.

Luescher, T.M. (2018). Altbach's theory of student activism in the twentieth century: Ten propositions that matter. In Jodi Burkett (Ed.), Students in twentieth century Britain and Ireland. Palgrave MacMillan. https://doi.org/10.1007/978-3-319-58241-2_13

Mannan, M. (2007). Student Attrition and academic and social integration: Application of Tinto's model at the University of Papua, New Guinea. Higher Education, 53, 147-165. https://doi.org/10.1007/ s10734-005-2496-y

Marinoni, G., Van't Land, H. \& Jensen, T. (2020). The impact of Covid-19 on higher education around the world. International Association of Universities Global Survey. International Association of Universities Publishers. https://www.iau-aiu.net/IMG/pdf/iau_covid19_and_he_survey_report_ final_may_2020.pdf

Marope, P.T. (2019). Education: The key to development. Prospects, 47, 305-307. https://doi.org/10.10 07/s11125-019-09454-0

McCarthy, C. (2020). Review colleagues' lessons learned for managing impact of COVID-19 crisis. Student Affairs Today, 23(3), 1-5. Wiley Periodicals Publishers. https://doi.org/10.1002/say.3074

McCubbin, I. (2003). An examination of criticism made of Tinto's 1975 student integration model of attrition. https://www.psy.gla.ac.uk/ steve/localed/icubb.pdf [Accessed 4 October 2020].

Monnapula-Mapesela, M. (2017). Students' perception of own preparedness for higher education: Case study. International Journal of Educational Sciences, 9(2), 255-264. https://doi.org/10.1080/09751122. 2015.11890315

NSFAS (2020). South African National Student Financial Aid Scheme guidelines. https://bit.ly/3rorWhN

Osfield, K., Perozzi, B., Bardill Moscaritolo, L. \& Shea, R. (2016). Supporting students globally in higher education:Trends and perspectives for student affairs and services. NASPA Publishers.

Pascarella, E. \& Terenzini, P. (2005). How college affects students: Findings and insights from twenty years of research. Jossey-Bass.

Peercy, C. \& Svenson, N. (2016). The role of HE in equitable human development. International Review of Education, 62,139-160. https://doi.org/10.1007/s11159-016-9549-6 
Salganik, M. \& Heckathorn, D. (2004). Sampling and estimation in hidden populations using respondentdriven sampling. Sociological Methodology, 34(1), 193-239. https://doi.org/10.1111/j.0081-1750.20 04.00152.x

Schendel, R. \& McCowan, T. (2016). Expanding higher education systems in low- and middle-income countries: The challenges of equity and quality. Higher Education, 72, 407-411. https://doi.org/ 10.1007/s10734-016-0028-6

Schreiber, B. (2013). Using Bernstein's notion of re-contextualising fields to understand the challenges around integration of discursive and formal communities at UWC. Paper presented at the UWC Teaching \& Learning Colloquium. Cape Town, 19 July. http://www.youtube.com/watch?v=9ew $\mathrm{JCd} 2 \mathrm{HcBQ}$

Schreiber, B. (2014). The role of Student Affairs in promoting social justice in South Africa. Journal of College \& Character, 15(4), 211-218. https://doi.org/10.1515/jcc-2014-0026

Schreiber, B., Bardill Moscaritolo, L., Perozzi, B. \& Luescher, T. (2020). The impossibility of separating learning and development. University World News. https://www.universityworldnews.com/post.php? story $=2020090210200929$

Schreiber, B., Luescher, T. \& Moja, T. (2019). Living communities. Journal of Student Affairs in Africa, 7(2), v-vii. https://doi.org/10.24085/jsaa.v7i2.3820

Schreiber, B. \& Lewis, J. (2020). Professionalization of student affairs and services around the world: More than a matter of degree(s). In R. Ludeman \& B. Schreiber (Eds.), Student Affairs \& Services in Higher Education: Global Foundations, Issues, and Best Practices (3rd ed., pp. 57-63). Deutsches Studentenwerk Publishers.

Scott, I. (2009). First-year experience as terrain of failure or platform for development? Critical choices for higher education. In B. Leibowitz, A. van der Merwe \& S. van Schalkwyk (Eds.), Focus on First-Year Success: Perspectives from South Africa and beyond. African Sun Media. https://doi.org/10.18 820/9781920338220/01

Smith, R.A. (2019). Structuring the conversations: Using co-citation networks to trace 60 years of The Journal of College Student Development. Journal of College Student Development, 60(6), 695-717. https://doi.org/10.1353/csd.2019.0063

Somerville, K. (2017). Africa's long road since independence: The many histories of a continent. Penguin Publishers.

Strydom, F., Kuh, G. \& Loots, S. (Eds.) (2017). Engaging students: Using evidence to promote student success. African Sun Media. https://doi.org/10.18820/9781928424093

Swingler, H. (2018, 20 July). Adopt Mbembe's 'pedagogies of presence'. UCT News. https://www. news.uct.ac.za/article/-2018-07-20-adopt-mbembes-pedagogies-of-presence-lis-lange [Accessed 23 September 2020].

Tesar, M. (2020). Towards a post-Covid-19 'new normality?': Physical and social distancing, the move to online and higher education. Policy Futures in Education, 18(5), 556-559. https://doi.org/ $10.1177 / 1478210320935671$

Tinto, V. (1993). Leaving college: Rethinking the causes and cures of student attrition (2nd ed.). University of Chicago Press. https://doi.org/10.7208/chicago/9780226922461.001.0001

Tinto, V. (1997). Classroom as communities: Exploring the educational character of student persistence. The Journal of Higher Education, 68(6), 599-623. https://doi.org/10.1080/00221546.1997.11779003

Tinto,V. (1998). Taking research on student persistence seriously. Review of Higher Education, 21(2), 167-177.

Tinto, V. (2014). Tinto's South Africa lectures. Journal of Student Affairs in Africa, 2(2), 5-28. https://doi. org/10.14426/jsaa.v2i2.66

Torres, V., Jones, S. \& Renn K. (2019). Student Affairs as a low-consensus field and the evolution of student development theory as foundational knowledge. Journal of College Student Development, 60(6), 645-658. https://doi.org/10.1353/csd.2019.0060 
Trowler, V. (2010). Student engagement literature review. Higher Education Academy, York.

Trowler, V. \& Schreiber, B. (2020). Student engagement from beyond the US: Increasing resonance through reframing the construct. Journal of College and Character, 21(4), 315-322. https://doi.org/ 10.1080/2194587X.2020.1822878

UNDP (2020). Rivera, C., Hsu,Y., Esbry, F. \& Dugarova, E. (2020). Gender inequality and the COVID-19 crisis. http://hdr.undp.org/sites/default/files/gendercovid_final.xlsx

UNESCO (2018).w Definition of regions. https://unesdoc.unesco.org/ark:/48223/pf0000261751/ PDF/261751eng.pdf.multi.page $=142$

Weidman, J. (1984). Impacts of campus experiences and parental socialization on undergraduates' career choices. Research Higher Education, 20(4), 445-476. https://doi.org/10.1007/BF00974923

Weidman, J. (1989). Undergraduate socialization: A conceptual approach. In J. Smart (Ed.), Higher Education: A handbook of theory and research (pp. 289-322). Agathon.

Wilson-Strydom, M. (2017). Disrupting structural inequalities of higher education opportunity: "grit", resilience and capabilities at a South African university. Journal of Human Development and Capabilities, 18(3), 384-398. https://doi.org/10.1080/19452829.2016.1270919

\section{How to cite:}

Schreiber, B., Luescher,T.M., Perozzi, B. \& Bardill Moscaritolo, L. (2021). Student Affairs and Services during Covid-19 in Africa: Mitigating the Pandemic's Impact on Student Success. Journal of Student Affairs in Africa, 9(1), 1-21. DOI: 10.24085/jsaa.v9i1.1425 